\title{
Prevalence and Vulnerability to Drug Abuse among Students of High School and Colleges in Riyadh, Saudi Arabia: Cross-Sectional Study
}

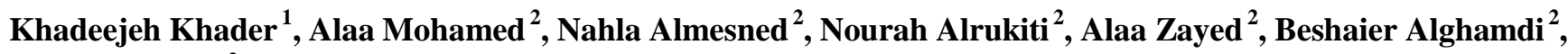 \\ Hind Al Shehri ${ }^{2}$
}

${ }^{1}$ Pharm. D, BCPS, Lecturer at AlMaarefa University, Riyadh, Saudi Arabia

${ }^{2}$ Pharm. D., Students - AlMaarefa University, Riyadh, Saudi Arabia

*Corresponding author - Khadeejeh Khader, khadijah.khader@gmail.com

Received 31 January 2019;

Accepted 19 February 2019;

Published 23 February 2019

\begin{abstract}
Background: Drug and substance abuse is a significant burden worldwide. This problem affects many families in each community in a way or another. By the end, the misuse of these substances can lead to health associated problems in addition to social, economic, and legal issues. The Students' susceptibility to drug abuse depends on different factors such as low self-esteem or to gain acceptance. Objectives: To compare the attitude of drug abuse between high school students and college students and to assess the common reasons that led to increase number of abusers. Methods: The study was conducted between February and May 2018 in Riyadh city on colleges and high schools students. A sample of 935 students aged between 15 and 25 years were randomly selected by distributing an online self-administered questionnaire for data collection. Results: The overall prevalence of drug abuse in Riyadh city was $18.94 \%$ among high school students $(8.07 \%$ and $10.87 \%$ female abusers) and $24.14 \%$ among college students (13.87\% male and $10.28 \%$ female abusers). A significant relationship was found between abuse and being a male students in college. The prevalence was different for high schools, the most widely abused substance was alcohol (44.5\%) followed by Hashish (40.19\%). These were used for different reasons the most common was for fun followed by escaping from problems. $\underline{\text { Conclusion: }}$ The study demonstrated that college students have higher prevalence and vulnerability to drug abuse than high school students, with the most commonly used substances being Alcohol and Hashish. According to our findings, the main reasons behind students' abuse of drugs are due to boredom thus wanting to have fun and having problems so they escape from them by drugs. Due to the prevalence of drug abuse and the various reasons behind it as demonstrated in our study, we believe that parents should be more involved with their children's lives, students should be encouraged to have hobbies in their spare time and guidance should be provided for them in order to learn how to deal with their problems correctly.
\end{abstract}

Keywords: drug abuse, students, high school, college, alcohol, Riyadh.

\section{Introduction}

Drug and substance abuse is one of the significant burdens worldwide ${ }^{[1]}$. According to World Health Organization, substance abuse refers to the continuous user consumption of drugs and substances such as alcohol, psychoactive and illicit drugs in a harmful or hazardous manner to themselves as well as to others ${ }^{[2]}$. This problem affects most of the families in each community in a way or another. In 2012 approximately 5\% of total population (230 million) used an illicit substance ${ }^{[3]}$. The misuse of these substances by the end can lead to health, social, economic, and legal issues ${ }^{[4]}$.

The Students' susceptibility to drug abuse depends on different situations or factors, such as; Low self-esteem, to gain acceptance and admiration from his/her squad while trying to create their personalities ${ }^{[5]}$. Another cause of abuse is the stress during examination periods; these drugs can be mistakenly used to boost their concentration ${ }^{[6]}$. Others can use it due to their family and friends influences', to mimic a parent, or a friend's cultural behavior. Furthermore, parents' educational level may be an important factor that reflects their awareness towards drugs' abuse. Considering the low family income and the employments of parents may also contribute to abuse. Adding to that the psychological status, especially in somber situations ${ }^{[7,8,9]}$.

Almost all of the previous studies showed that drug abuse appear to be a major problem among university and high school students, especially in youth and young adults (15-25 years $)^{[10]}$. 
Our study will shed the light on the major common causes that make this age group targeted and which factors increase their susceptibility to illicit drugs. There are no sufficient studies to connect the relation between high school and college students with different possible factors influencing their medication misuse in Saudi Arabia particularly in Riyadh district.

A similar study in Riyadh in 2014, examined students attitude towards OTC medications use during examination, it reported that $5 \%$ increased usage of energy drinks, with higher percentage for females than in males ${ }^{[11]}$.

This study will discuss the most substances abused in Riyadh like: alcohol, cannabis, khat, cocaine, Tramadol, heroine, tranquilizers, methamphetamines, OTC medications, opioids, hallucinogens, B Blockers, antihistamines, antidepressants, caffeine, Energy drinks, Traditional medicine, Glue, Polish remover, Thinner, Gasoline, Detergents and Pregabalin.

We estimate that our results will show comparable outcome to a previous study conducted in Abha City in 2016, on substance abuse among male secondary school students. It revealed that $68 \%$ of abuser student's average age was 17-18. Other results showed that $9.3 \%$ of their sampled students were alcohol abusers and $8.8 \%$ were substance abusers ${ }^{[12]}$

\section{Methodology}

This cross-sectional study was conducted in Riyadh city; it was started on February and continued till May in 2018. An ethical approval of the study design was obtained from research committee of Al-Maarefa University. Participation in our study was voluntary, before filling each questionnaire participants had to check a box assuring that the data will be collected anonymously to be used for research purposes only.

Data was collected by Google Surveys, we used a 42 - items pilot tested self-administered online questionnaire in Arabic language, and it was distributed via social media (whatsapp, twitter, facebook and snapchat) among high school and university students. The questionnaire was validated by other staff members whom are experts in the medical field.

It consisted of two parts, first part included questions about participants demographics (gender, nationality, age group, marital status, living status, family in-come, monthly allowance, educational level, GPA, medical condition, smoking cigarettes/hookah, packets/ day, age when first started smoking, source they obtained smoking habit from, if family knows about smoking, ability to stop smoking, substances abuse, frequency of abuse/ month, if abusing more than one substance at the same time, age when first started drug abuse, if they still using these substances, reasons of substance abuse, if they felt guilty because of substance abuse, if they could spend the week without drug abuse, their ability to stop drug abuse, if they had suffered from a medical problem and they were asked to define this problem, if they seek help to stop smoking/ abusing, registration in a rehabilitation program, withdrawal symptoms, had higher grades, failed in a course, reduced ambition, if their family knows about being abuser, if they had another smoker or abuser in the family and they were asked to determine the relative relation, economical issues and illegal issues).
Second part was study-related questions, about drugs and substances abused which were ( Alcohol, Khat, Tramadol, Cocaine, Flakka, Heroine, Hashish, Pregabalin, Tranquilizers, Methamphetamine, LSD, Beta blockers, Antihistamine, Antidepressants, Cough medications, Glue, Acetone, Correctors, Paints, Thinners, Gasoline, Detergents, Pain killers, Sleeping pills, Laughing gas, Lighter gas)

A total of 1244 volunteers participated in this study from both genders male and female. Inclusion criteria resulted in only 935 participated students of high schools and colleges with age between 15-25 years old and were studying in the city of Riyadh.

Data analysis was carried out using GNU PSPP 1.0.1, the results were reported as frequencies and percentages. Comparison between the variables was tested using Chi- square and it was carried by Independent samples $T$ test. A p-value of $<0.05$ was considered statistically significant.

\section{Results}

Out of 1244 responses, 935 were valid after excluding those who were not students, who were out of the age group range (1525 years old) and those who were studying outside the city of Riyadh. Of 935 total there were 322 (34.4\%) responses from high school students and $613(65.56 \%)$ from college students. For high school there were $142(44.10 \%)$ male students and $180(55.90 \%)$ female students, and for college students there were 298 (48.61\%) male students and $315(51.39 \%)$ female students. Overall, the higher participation was seen from female participants.

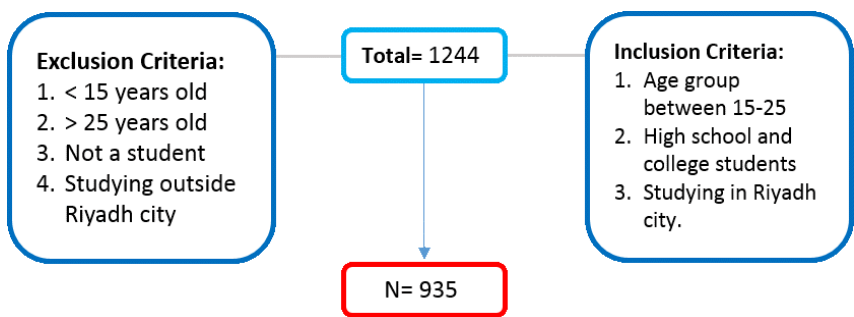

Table1: Demographic characteristics of participants, $\mathbf{N}=935$.

\begin{tabular}{lcc}
\hline Institution & $\boldsymbol{N}$ & $\%$ \\
\hline High school & 322 & $34.4 \%$ \\
College & 613 & $65.56 \%$ \\
Gender & & \\
Male & 440 & $47.05 \%$ \\
Female & 495 & $52.94 \%$ \\
\hline
\end{tabular}

For high school students, there were $45(13.97 \%)$ male students who were tobacco smokers and $27(8.39 \%)$ female smokers. For college students there were 155 (25.29\%) male smokers and 57 $(9.30 \%)$ female smokers. The higher percentage of smoking was seen among males than females, that showed a significant relationship between smoking and gender $(\mathrm{P}$ value $=0)$.

Table2: Smoking among students in relation to gender.

\begin{tabular}{lcc}
\hline Smoke & Yes & No \\
\hline High school & & \\
Male & $13.97 \%$ & $30.12 \%$ \\
Female & $8.39 \%$ & $47.52 \%$ \\
College & & \\
Male & $25.29 \%$ & $23.33 \%$ \\
Female & $9.30 \%$ & $42.09 \%$ \\
\hline
\end{tabular}


Table 3: $\mathbf{P}$ value of smoking in relation to gender

\begin{tabular}{lll}
\hline & $P$ value & Relationship \\
\hline High school & 0 & Significant \\
College & 0 & Significant \\
\hline
\end{tabular}

The total number of participants who admitted substance abuse among high school were $61(18.94 \%)$ students, 26 (8.07\%) were male students and $35(10.87 \%)$ were female students, this indicated that there was no relationship between gender and substance abuse among high school students $(\mathrm{P}$ value $=0.769)$.

In contrast to high school students, there were 148 (24.14\%) drug abusers among college students, 85 (13.87\%) were male students and $63(10.28 \%)$ were female students that displayed a significant relationship between genders and being an abuser. $(\mathrm{P}$ value $=0.014)$

Table 4: Substances abuse among students in relation to gender

\begin{tabular}{lcc}
\hline Abusers & Yes & No \\
\hline High school & & \\
Male & $8.07 \%$ & $36.02 \%$ \\
Female & $10.87 \%$ & $45.03 \%$ \\
College & & \\
Male & $13.87 \%$ & $34.75 \%$ \\
Female & $10.28 \%$ & $41.11 \%$ \\
\hline
\end{tabular}

Table5: $P$ value of drug abuse in relationship to gender

\begin{tabular}{lcc}
\hline & P value & Relationship \\
\hline High school & 0.769 & No relationship \\
College & 0.014 & Significant \\
\hline
\end{tabular}

Out of total smokers there were 257 (90.49\%) students who were living with their families, $19(6.69 \%)$ students who were living alone and $8(2.81 \%)$ students were living with a roommate. Which denoted that there was a significant relationship between being a smoker and the living status $(P$ value $=0) .48 \%$ of those smoker students answered with yes when they were asked if their family knows about their smoking.

Out of our total number of students who abuse drugs, 193 $(92.34 \%)$ of them were living with their families, $11(5.26 \%)$ students were living alone and $5(2.39 \%)$ students were living with a roommate $(\mathrm{P}$ value $=0.161) .15 \%$ of those students responded with yes when they were asked if someone in their family knows about them being a drug abuser.

Table 6: Smoking and substances abuse among students in relation to their living status

\begin{tabular}{lcccc}
\hline & \multicolumn{2}{c}{ Smokers } & \multicolumn{2}{c}{ Abusers } \\
\hline & $N$ & $\%$ & $N$ & $\%$ \\
With Family & 257 & $90.49 \%$ & 193 & $92.34 \%$ \\
Alone & 19 & $6.69 \%$ & 11 & $5.26 \%$ \\
Roommate & 8 & $2.81 \%$ & 5 & $2.39 \%$ \\
Family knows & & $48 \%$ & & $15 \%$ \\
\hline
\end{tabular}

Table7: $P$ value of smoking and drug abuse in relationship to living status.

\begin{tabular}{lll}
\hline & P value & Relationship \\
\hline Smoking & 0 & Significant \\
Drug abuse & 0.161 & No relationship \\
\hline
\end{tabular}

According to our findings, there were 53 (18.66\%) smokers and $51(24.40 \%)$ drug abusing student with a monthly allowance of less than 500 SR. For those with allowance between 500 to 1,000 SR monthly there were 92 (32.39\%) smokers and 68 (32.54\%) abusers. For those who get more than 1,000 but less than 2,000 SR there were $77(27.11 \%)$ smokers and $51(24.40 \%)$ abusers. And for the last category, students with more than 2,000 SR monthly, there were $62(21.83 \%)$ smokers and $39(18.66 \%)$ abusers. Thus, these statistics showed that there was no relationship between having higher monthly allowance and being a smoker or abuser.

Table8: Smoking and drug abuse among students in relation to their monthly allowance

\begin{tabular}{lcccc}
\hline & \multicolumn{2}{c}{ Smokers } & \multicolumn{2}{c}{ Abusers } \\
\hline & $N$ & $\%$ & $N$ & $\%$ \\
Less than 500 SR & 53 & $18.66 \%$ & 51 & $24.40 \%$ \\
500 - 1,000 SR & 92 & $32.39 \%$ & 68 & $32.54 \%$ \\
$\mathbf{1 , 0 0 0}-\mathbf{2 , 0 0 0 ~ S R}$ & 77 & $27.11 \%$ & 51 & $24.40 \%$ \\
More than 2,000 SR & 62 & $21.83 \%$ & 39 & $18.66 \%$ \\
\hline
\end{tabular}

Table9: $P$ value of smoking and drug abuse in relationship to monthly allowance

\begin{tabular}{lcc}
\hline & P value & Relationship \\
\hline Smoking & 0 & Significant \\
Drug abuse & 0 & Significant \\
\hline
\end{tabular}

The reasons associated with drug abuse were numerous but abusing drugs for Fun was the most common with (66.02\%) students, followed by escaping from problems with (40.66\%), Family problems (24.4\%), Psychological problems (19.12\%), Influence of Friends (18.18\%), sleeping problems (13.87\%), and other reasons shown in table 10 .

Table10: Percentages of reasons students abuse drugs.

\begin{tabular}{lc}
\hline Reasons & Percentages \\
\hline For Fun & $66.02 \%$ \\
\hline Exam & $11.48 \%$ \\
\hline Availability & $7.65 \%$ \\
To be more confident & $6.22 \%$ \\
Get rid of being shy & $9.09 \%$ \\
\hline Escaping Problems & $40.66 \%$ \\
\hline Family Problems & $24.4 \%$ \\
\hline Financial Problems & $11 \%$ \\
\hline Psychological Problems & $19.12 \%$ \\
\hline Advertising & $2.39 \%$ \\
\hline Sleeping Problems & $13.87 \%$ \\
\hline Influence Friends & $18.18 \%$ \\
\hline
\end{tabular}

Most drugs were first used when the students were above 16 years old with $71.83 \%$, followed by ages between 14 to 16 years old with $16.9 \%$.

Table 11: Age students started to abuse.

\begin{tabular}{lll}
\hline Age & $N$ & $\%$ \\
\hline$<\mathbf{1 0}$ years & 9 & $6.33 \%$ \\
$\mathbf{1 1} \mathbf{- 1 3}$ years & 7 & $4.90 \%$ \\
$\mathbf{1 4}-\mathbf{1 6}$ years & 24 & $16.9 \%$ \\
$>\mathbf{1 6}$ years & 102 & $71.83 \%$ \\
\hline
\end{tabular}

The most widely used substance was Alcohol with (44.5\%), after that Hashish (40.19\%), Acetone (22.97\%), Correctors $(20.57 \%)$, Glue $(17.7 \%)$, Tranquillizers $(16 \%)$, followed by others shown in Table12. 
Table 12: Percentages of Substances abused.

\begin{tabular}{lcc}
\hline Substances & \multicolumn{2}{c}{$\%$} \\
\hline & Use & Don't use \\
\hline Alcohol & $44.5 \%$ & $55.5 \%$ \\
\hline Hashish & $40.19 \%$ & $59.81 \%$ \\
\hline Acetone & $22.97 \%$ & $77.03 \%$ \\
\hline Corrector & $20.57 \%$ & $79.43 \%$ \\
\hline Glue & $17.7 \%$ & $82.3 \%$ \\
\hline Tranquilizers & $16.75 \%$ & $83.25 \%$ \\
\hline Cough Medication & $15.79 \%$ & $84.21 \%$ \\
\hline Detergents & $14.83 \%$ & $85.17 \%$ \\
\hline Antihistamines & $14.35 \%$ & $85.65 \%$ \\
\hline Gasoline & $13.88 \%$ & $86.12 \%$ \\
\hline Antidepressants & $12.92 \%$ & $87.08 \%$ \\
\hline Pregabalin & $11.96 \%$ & $88.04 \%$ \\
\hline Paints & $11.96 \%$ & $88.04 \%$ \\
\hline Tramadol & $8.61 \%$ & $91.39 \%$ \\
\hline Methamphetamine & $8.13 \%$ & $91.87 \%$ \\
\hline LSD & $7.18 \%$ & $92.82 \%$ \\
\hline Thinners & $6.22 \%$ & $93.78 \%$ \\
\hline Cocaine & $5.26 \%$ & $94.74 \%$ \\
\hline Khat & $3.35 \%$ & $96.65 \%$ \\
\hline Beta blockers & $3.35 \%$ & $96.65 \%$ \\
\hline Heroine & $1.91 \%$ & $98.09 \%$ \\
\hline The & & \\
\hline
\end{tabular}

The rate at which students who abuse substances use their drugs on a monthly basis was categorized between Less than 5 times (51.67\%), 5 to 10 times(10.52\%), more than 10 times(8.61\%).

Table13: Percentages of the frequency students abuse drugs per month.

\begin{tabular}{lcc}
\hline Times/Month & N & \% \\
\hline$<\mathbf{5}$ Times & 108 & $72.90 \%$ \\
$\mathbf{5}$ - 10 Times & 22 & $14.86 \%$ \\
$>\mathbf{1 0}$ Times & 18 & $12.16 \%$ \\
\hline
\end{tabular}

Some students had higher grades after using Tobacco or taking substances with $24.88 \%$, and some got lower graders or it did not have any effect with $70.81 \%$ as shown in Table14.

Students who think they have failed a course due to substance use are $16.74 \%$, and the percentage of students that did not fail is $78.94 \%$ as shown in Table15.

Table 14: Relationship between using tobacco or drugs and having higher grades

\begin{tabular}{lll}
\hline Grades & $N$ & $\%$ \\
\hline Higher & 52 & $24.88 \%$ \\
Same or Lower & 148 & $70.81 \%$ \\
\hline
\end{tabular}

Table 15: Relationship between using Tobacco or drugs and Failing a course

\begin{tabular}{lcc}
\hline & $N$ & $\%$ \\
\hline Failed & 35 & $16.74 \%$ \\
Did not Fail & 165 & $78.94 \%$ \\
\hline
\end{tabular}

21 students $(10.04 \%)$ of abusers had disease associated to their abuse, most common was amnesia with $6.22 \%$, followed by confusion $1.43 \%$, convulsions with $0.95 \%$, and other diseases as shown in Table16.
Table 16: Percentage of drug abuse related diseases.

\begin{tabular}{lc}
\hline Diseases & Percentages \\
\hline Amnesia & $6.22 \%$ \\
Confusion & $1.43 \%$ \\
Insomnia & $0.43 \%$ \\
Headache & $0.43 \%$ \\
Convulsion & $0.95 \%$ \\
Hemoptysis & $0.43 \%$ \\
\hline
\end{tabular}

\section{Discussion}

A significantly higher percentage of smokers are seen in male students from high schools and colleges. It may be due to environmental influences; males are usually exposed to cigarettes more than females. Also, the social acceptance plays a major role, in our society it is accepted to see a male smoker but it is not the same for females. In a previous study, males had a higher smoking ratio than females ${ }^{[13]}$.

According to our study, living conditions do affect the smoking habit. Students who are living with their families had the highest percentage with $(90.49 \%) .48 \%$ of smokers' families are aware about their smoking habit. That means around half of the smoking cases are done in front of their family sight.

Our findings indicate that the prevalence of drug abuse among students in college is directly related to the gender. Male students have the higher percentage of abusing substances. But, for high school students it is higher in female than in male students. This may be due to the small sample size we have. In a similar study conducted in Riyadh approximately $66.6 \%$ of female students and $44.4 \%$ of male students experienced anxiety or depression, this may lead them to abuse drugs more than males ${ }^{[14]}$.

Most of drug abuser students are living with their families with a percentage of $(92.34 \%)$. Only $15 \%$ of their families are aware about their substance abuse. This indicates that there is no relationship between the living condition and abuse potential.

Most of smokers and abusers have a monthly allowance between 500-1000 SR. This had an insignificant $p$ value, thus there is no relationship between monthly allowance and being smoker or abuser.

The most commonly abused substances among high school and college students are Alcohol at the top with (44.5\%), then followed by Hashish (40.19\%), Acetone (22.97\%), Correctors (20.57\%), Glue (17.7\%), Tranquillizers (16\%), cough, detergents, antihistamines, gasoline, antidepressants, paints, pregabalin, tramadol, methamphetamine, LSD, thinners, cocaine, khat, beta blockers, heroine, flakka, painkillers, sleeping pills, laughing gas, and lighters gas arranged highest to the lowest frequencies.

In a similar study conducted in Riyadh, it showed that alcohol, amphetamines, heroin and cannabis were the most frequently abused substances in the community. And some of these substances are easier to find and more available than others ${ }^{[15]}$.

The majority of abusers use these substances less than 5 times per month (51.67\%). Tendency to abuse these substances is arranged from highest to lowest, starting from those who are abusing drugs just to have fun $(14.76 \%)$, escaping from problems (9.09), having family problems (5.45\%), psychological Problems 
(4.28\%), influence of friends $(4.06 \%)$, and sleeping problems (3.1\%). These results are comparable to other similar results show that most respondents use substances when they are bored, tired or stressed, or parties to relax and relive stress ${ }^{[16] \text {. }}$

Most of abusers are 16 years and older (48.8\%). This is comparable to a recent study on substance abuse among male school students revealed that $68 \%$ of abusers are with average age of 17 to 18 . This may be due to feeling more independent and curious to experience these substances ${ }^{[17]}$.

The schooler achievement is found to be affected by abusing substances. Around $25 \%$ of student had higher grades and about $17 \%$ had failed a course due to abuse.

\section{Conclusion}

Our study demonstrated that college students have higher prevalence and vulnerability to drug abuse than high school students, the most commonly used substances are Alcohol and Hashish. The main reason behind students' abuse is boredom and wanting to have some fun, also encountering some problems makes them want to escape by abusing drugs. Due to the prevalence of drug abuse and the various reasons behind it as demonstrated in our study, we believe that parents should be more involved with their children's lives, students should be encouraged to have hobbies in their spare time and guidance should be provided for them in order to learn how to deal with their problems correctly.

\section{Limitations}

- Time frame was insufficient, so the questionnaires haven't reached the desired number of high school students.

- It was harder for us to reach male students due to some cultural boundries.

\section{Recommendations}

- Conducting this study in other cities of Saudi Arabia.

\section{Acknowledgment}

Special thanks to Dr.safia Dawood and Dr. Aisha Dawood from computer science department of Almaarefa University for their help in our statistical part of this research.

\section{References}

[1] Nutt D, L. king et al. Development of a rational scale to assess the harm of drugs of potential misuse, The Lancet 2007 March 24; 369( 9566):1047-1053

[2] World Health Organization. Substance abuse; URL: http://www.who.int/topics/substance_abuse/en/

[3] 2012 World Drug Report. Available from URL: https://www.unodc.org/documents/data-andanalysis/WDR2012/WDR_2012_web_small.pdf
[4] Al-Umran, K., Mahgoub, O. and Qurashi, N. Volatile Substance Abuse among School Students of Eastern Saudi Arabia. Annals of Saudi Medicine, 1993; 13(6), pp.520-524.

[5] Newcomb MD, Maddahian E, Bentler PM. Risk factors for drug use among adolescents: concurrent and longitudinal analyses. Am J Public Health. 1986; 76:525-531. doi: 10.2105/AJPH.76.5.525.

[6] Firth J. Level and sources of stress in medical students. Br Med J. 1996; 292:1117-80.

[7] H M Al-Musa, S D Al-Montashri. Substance abuse among male secondary school students in Abha City, Saudi Arabia: prevalence and associated factors. 2016 April 17; 27(4).

[8] Omokhodion FO, Gureje O. Psychosocial problems of clinical students in the University of Ibadan Medical School. Afr J Med Med Sci. 2003; 32:55-8.

[9] EO Babalola, A Akinhanmi, A Ogunwale. Who Guards the Guards: Drug Use Pattern Among Medical Students in a Nigerian University. Babalola E et al. Ann Med Health Sci Res. 2014 May-Jun; 4(3): 397-403.

[10] Al-Umran, K., Mahgoub, O. and Qurashi, N. (1993). Volatile Substance Abuse among School Students of Eastern Saudi Arabia. Annals of Saudi Medicine, 13(6), pp.520-524.

[11] H Almalak, A I Albluwi, DA Alkhelb, H M Alsaleh, TM Khan, M A Hassali, et al. Students' attitude toward use of over the counter medicines during exams in Saudi Arabia. Almalak H et al. Saudi Pharm J. 2014 April; 22(2):107-11

[12] H M Al-Musa, S D Al-Montashri. Substance abuse among male secondary school students in Abha City, Saudi Arabia: prevalence and associated factors. 2016 April 17; 27(4).

[13] Lukoye A, Prisca A M, Moses N N, Kiende C K, and Evans MO. Prevalence of substance use among college students in Eldoret, western Kenya. BMC Psychiatry. 2011 Feb 28; 11:34.

[14] Ahmed A.S, Abdualltef H.R, Abdulrhman A.E, Abdullah M.A, Abdullah H.H, Albaraa A.J, et al. Sedative Drug Use among King Saud University Medical Students: A Cross-Sectional Sampling Study. Depress Res Treat, 2014 Jan; 2014:378738.

[15] Al-Haqwi AI. Perception among medical students in Riyadh, Saudi Arabia, regarding alcohol and substance abuse in the community: a cross-sectional survey.Subst Abuse Treat Prev Policy. 2010 Jan 22; 5:2.

[16] Lukoye A, Prisca A M, Moses N N, Kiende C K, and Evans MO. Prevalence of substance use among college students in Eldoret, western Kenya. BMC Psychiatry. 2011 Feb 28; 11:34.

[17] H M Al-Musa, S D Al-Montashri. Substance abuse among male secondary school students in Abha City, Saudi Arabia: prevalence and associated factors. 2016 April 17; 27(4). 